\title{
BMJ Open Patient characteristics related to the need for peer support in rehabilitation after acquired brain injury: a prospective cohort study in the Netherlands
}

\author{
Ruth Wobma, ${ }^{1}$ Rinske Nijland, ${ }^{1}$ Gert Kwakkel ${ }^{1,2,3}$
}

To cite: Wobma R, Nijland R, Kwakkel G. Patient characteristics related to the need for peer support in rehabilitation after acquired brain injury: a prospective cohort study in the Netherlands. BMJ Open 2019;9:e025665. doi:10.1136/ bmjopen-2018-025665

- Prepublication history and additional material for this paper are available online. To view please visit the journal (http:// dx.doi.org/10.1136/bmjopen2018-025665).

Received 26 November 2018 Revised 12 June 2019 Accepted 14 June 2019

Check for updates

(c) Author(s) (or their employer(s)) 2019. Re-use permitted under CC BY-NC. No commercial re-use. See rights and permissions. Published by BMJ.

\section{${ }^{1}$ Department of}

neurorehabilitation, Amsterdam Rehabilitation Research Centre, Amsterdam, The Netherlands ${ }^{2}$ Department of Rehabilitation Medicine, Amsterdam University Medical Centre, Amsterdam

Movement Sciences, Amsterdam Neurosciences, Amsterdam, The Netherlands

${ }^{3}$ Department of Physical Therapy and Human Movement Sciences, Northwestern University, Chicago, USA

Correspondence to

Dr. Ruth Wobma;

r.wobma@reade.nl

\section{ABSTRACT}

Objective Peer support facilitates patients and caregivers in adjusting to long-term disabilities. This study aimed to determine which patient characteristics are related to need for peer support during rehabilitation after acquired brain injury $(\mathrm{ABI})$ and investigate factors that explain whether peer support is perceived as meaningful or not.

Design A prospective cohort study over a period of 17 months following patients with $A B I$ during inpatient rehabilitation in the Netherlands. Multivariable logistic modelling was applied to identify patient and intervention characteristics that were related to (1) need for peer support and (2) whether or not peer support was perceived as meaningful. Additional information on duration and subjects of conversation was reported.

Setting Peer support was provided during inpatient rehabilitation.

Participants 120 patients with $A B I \geq 18$ years were included and assessed at admission, 94 patients were assessed at discharge. Seventy-three percent $(n=88)$ expressed a need for peer support and at discharge 76.6\% $(\mathrm{n}=72)$ perceived contact as meaningful.

Results Non-Western and single patients perceived a significantly higher need for peer support. Patients younger than 60 and those with time between $\mathrm{ABI}$ and discharge of $>3$ months perceived their contact significantly more meaningful.

Conclusions Results provide more insight into characteristics of patients with $A B I$ who may benefit from peer support during inpatient rehabilitation. Optimal dosage, length of contact, rehabilitation phase and strategy for the provision of peer support should be investigated as well as the effects for $\mathrm{ABI}$ survivors on outcomes such as coping, self-efficacy, depression and health-related quality of life.

\section{INTRODUCTION}

Acquired brain injury (ABI) is a major cause of disability. ${ }^{12}$ The majority of ABI survivors face a wide range of problems, such as motor impairments, cognitive impairments, speech and language problems, often resulting in a loss of independence in activities of daily
Strengths and limitations of this study

- Results provide more insight into characteristics of patients with acquired brain injury who may benefit from peer support during inpatient rehabilitation.

- Information about patients' expectations and experiences was gathered by asking patients to explain in more detail why they did or did not perceive a need for peer support and experienced the contact as meaningful.

- It is possible that some patients gave socially desirable responses to the questions about need for peer support and if it was meaningful.

- Patients with severe cognitive or communicative impairments were excluded from this study.

- The lack of a fixed protocol for peer support led to a greater variation in the outcome of 'meaningful contact'.

living (ADL) and a reduced health-related quality of life. ${ }^{34}$ A number of rehabilitation programmes are specifically designed to support patients after $\mathrm{ABI}$ in regaining participation in areas such as work, daily and social life. It has been recognised, however, that support of healthcare professionals in rehabilitation teams is insufficient to satisfy all patients' needs. ${ }^{5}$ To complement the regular rehabilitation programmes, it is suggested that additional support of peers is needed to add experiential knowledge to the rehabilitation process, which facilitates patients and caregivers in adjusting to long term disabilities. ${ }^{5}$ The United Nations Convention on the Rights of Persons with Disabilities ${ }^{6}$ considers peer support as a part of adequate rehabilitation management and the WHO has embraced this perception in the World Report on Disability (2011). ${ }^{7}$

At this moment there are two randomised controlled trials (RCTs) that have studied 
the effects of peer support on patients after traumatic brain injury (TBI). First, Struchen and colleagues report a significant improvement of perceived social support, social integration, size of social network and participation in highly valued activities. ${ }^{8}$ Second, Hanks et al describe significant changes with regard to better behavioural control, reduced alcohol use and less emotion-focused and avoidance-oriented coping. ${ }^{9}$ Beside the reported positive influences of peer support, the two RCTs also report negative effects. Supposedly due to an increased awareness of problems after TBI, patients reported more depressive symptoms ${ }^{8}$ and caregivers reported less social support and community integration. ${ }^{9}$ RCTs that investigate the effects of peer support programmes for people with other forms of ABI such as stroke or brain tumours are lacking in literature. ${ }^{10-12}$ Three qualitative studies have evaluated the impact of peer support and suggest favourable effects for stroke survivors ${ }^{13} 14$ as well as their caregivers. ${ }^{15}$ Earlier studies suggest that peer support may be beneficial to people who experience the consequences of ABI. However, there is a particular need for a better identification of patients who may benefit from peer support during rehabilitation. Characteristics such as time after injury, the match between the peer supporter and the patient in terms of similar cultural and demographic background, marital or family status, injury history, interests, ${ }^{16}$ gender and role ${ }^{89}$ need to be investigated. Therefore, the primary aim of this study was to determine which patient characteristics are related to the need for peer support after ABI. The second aim was to investigate factors that may explain whether peer contact is perceived as 'meaningful' or not by the patient with an ABI. It is hypothesised that the need for peer support will be higher for those patients who are socially more isolated ${ }^{17}$ and that it will be especially meaningful for patients who have a closer match to the peer supporter in terms of similar impairments derived from a comparable diagnosis, similar age, family and social status. ${ }^{515}$

\section{METHODS}

\section{Design}

This study is a prospective cohort study started in March 2014. Over a period of 17 months, 120 patients with ABI who followed inpatient rehabilitation in Reade rehabilitation centre were recruited and followed from admission to discharge as shown in figure 1.

The method section is reported following the recommendations of the Strengthening the Reporting of Observational studies in Epidemiology (STROBE) statement. ${ }^{18}$

\section{Participants}

ABI was defined as a collective term for acute (rapid onset) focal and non-focal brain injury, of any cause (and International Classification of Diseases (ICD) -10 codes). ${ }^{19} 20$ This definition includes:

- vascular accident (stroke or subarachnoid haemorrhage) (ICD codes: I60-I69).

- trauma - due to head injury or post-surgical damage (eg, following tumour removal) (ICD codes: S01-S09, T040 and T060, C700 C709 C710-C719 C751 C753 C793, D420 D429-D432 D439 D443 D445, D320 D329 D330-D332 D339 D352 D354).

- cerebral anoxia (ICD codes: G931).

- other toxic or metabolic insult (eg, hypoglycaemia) (ICD codes T58X, G92X G930 G934-G936 G938 G939).

- infection (eg, meningitis, encephalitis) or other inflammation (eg, vasculitis) (ICD codes: G00 G01 G020 G021 G028 G03 G04 G05 G060, A390 A392A394 A398 A399 A170 A171 A321 A83-A87 A811, B010 B003 B004 B011 B020 B021 B050 B051 B261 B262 B375 B451 B941, F071).

Patients with ABI were included in this study within 2 weeks after admission if they met the following inclusion criteria: (1) diagnosed with ABI, (2) age $\geq 18$ years, (3) Dutch or English speaking and 4) able to communicate and understand in order to bring forward his/her opinion. Informed consent was given by all participants

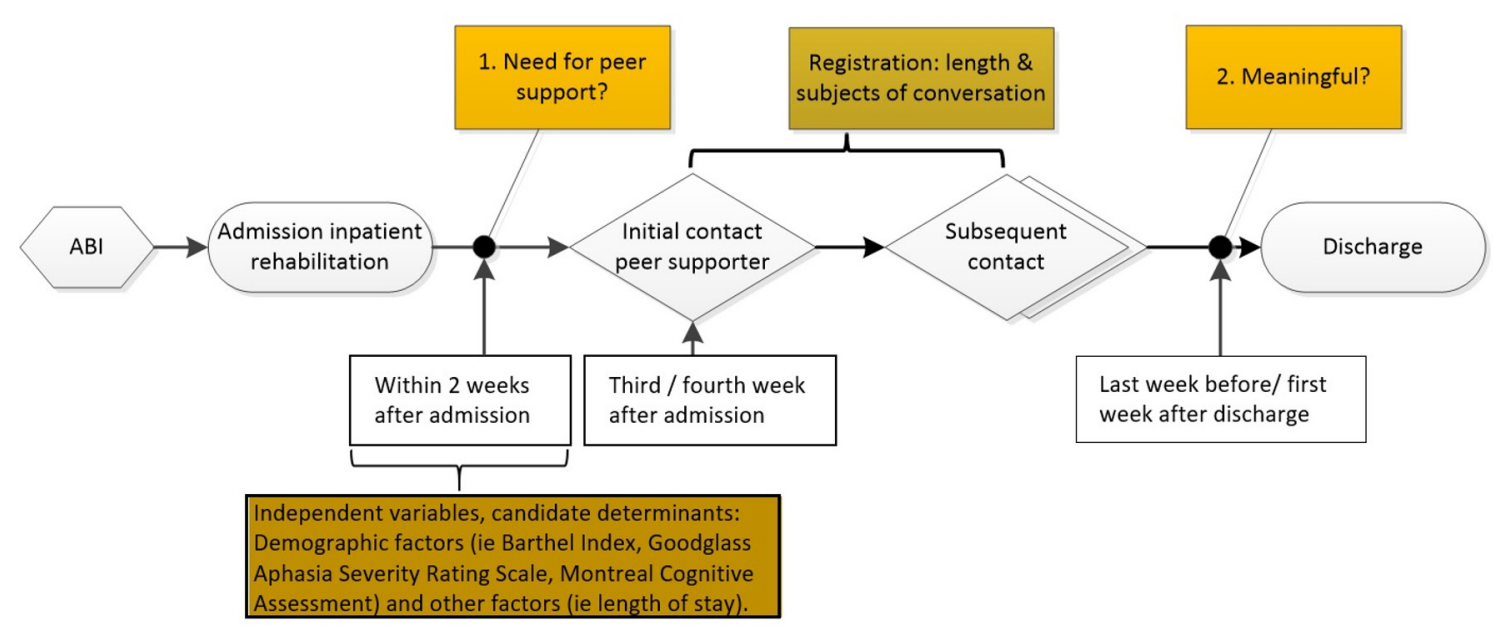

Figure 1 Design. 
Table 1 Characteristics of peer supporters

\begin{tabular}{|c|c|}
\hline Variable & $\begin{array}{l}\text { Peer supporters } \\
(\mathrm{n}=4)\end{array}$ \\
\hline \multicolumn{2}{|l|}{ Demographic factors } \\
\hline Gender, male (\%) & $2(50 \%)$ \\
\hline Mean age in years (SD) & $40.3(6.5)$ \\
\hline Cultural background, Western (\%) & $4(100 \%)$ \\
\hline Marital status, married or relationship (\%) & $2(50 \%)$ \\
\hline Children, yes (\%) & $3(75 \%)$ \\
\hline \multicolumn{2}{|l|}{ Educational level } \\
\hline \multicolumn{2}{|l|}{ Lower (\%) } \\
\hline \multicolumn{2}{|l|}{ Intermediate (\%) } \\
\hline Tertiary (\%) & $4(100 \%)$ \\
\hline \multicolumn{2}{|l|}{ Occupational status, working (\%) } \\
\hline Before ABI & $4(100 \%)$ \\
\hline After $\mathrm{ABI}$ & $0(0 \%)$ \\
\hline Sports, yes (\%) & $3(75 \%)$ \\
\hline \multicolumn{2}{|l|}{ Neurological factors } \\
\hline \multicolumn{2}{|l|}{ Type of $A B I$} \\
\hline ICVA (\%) & $1(25 \%)$ \\
\hline $\mathrm{ICH}(\%)$ & $1(25 \%)$ \\
\hline Trauma & $2(50 \%)$ \\
\hline
\end{tabular}

$\mathrm{ABI}$, acquired brain injury; ICH, intracerebral haemorrhage.; ICVA, ischaemic cerebrovascular accident; $n$, number of peer supporters.

and the peer supporters agreed to cooperate during the course of the research.

\section{Peer support programme}

Peer support was defined as: 'Social emotional support, offered by persons with experiential knowledge and with characteristics similar to the recipient. ${ }^{5}$ Peer support was provided by a team of four persons with ABI (details are shown in table 1) employed by the rehabilitation centre. They were specifically assigned and trained for their role. The training aimed to bring the level of experiential knowledge of the trainees from 'lay individuals' to 'peers' ${ }^{5}$ The training consisted of theory on peer support and $\mathrm{ABI}$ to help peers to intentionally use their own, as well as others' experiences of living with ABI to support patients currently in rehabilitation. Role plays on listening and motivational interviewing skills were done to train the provision of emotional and appraisal support ${ }^{5}$ and to be a role model in order to encourage and strengthen the patient in their rehabilitation process.

The cause of ABI differed among the available peer supporters, as well as age, gender, social status, length of rehabilitation, and so on. Peer supporters' disabilities due to cognitive, communication and motor impairments also varied. As a consequence, they formed a diverse group in which the variety of new ABI survivors could find similar characteristics and comparable experience.
The match between patient and peer supporter was based on the type of neurological impairments as a result of the brain injury. For instance, a patient who primarily suffered from cognitive impairments was matched with a peer supporter who had comparable impairments. Peer support was pragmatically embedded in the available rehabilitation services. With that, only the first moment of contact was planned; every patient was invited for a first session with a peer supporter in the third or fourth week after admission. Although this was planned as a $30 \mathrm{~min}$ session, the peer supporter and/or patient were free to deviate from that. Subsequent contact, the duration and subjects of conversation depended on the patients' preferences. In addition, there were no rules for ending or continuing peer support and therefore contact could be continued during outpatient rehabilitation services.

\section{Measurements}

Dependent variables of the research were (1) perceived need for contact with a peer supporter $(y / n)$, asked before the initial contact and (2) whether or not the contact with the peer supporter during inpatient rehabilitation was perceived as meaningful $(\mathrm{y} / \mathrm{n})$, asked at time of discharge.

Independent variables were demographic and neurological characteristics at time of admission. Demographic factors included: gender, age, cultural background, marital status, children (yes or no), educational level, occupational status and sports (yes or no). Cultural background was divided into Western; person with a cultural background from one of the countries in Europe (excluding Turkey), North America, Oceania, Indonesia or Japan, and non-Western; person with a cultural background from one of the countries in Africa, Latin America, Asia (excluding Indonesia and Japan) or Turkey. ${ }^{21}$ Marital status contained two groups: single (widowed/divorced or not in a relationship) and in a relationship (married, partners living together or in a relationship not living together). Educational level was divided into three groups: lower (no education, primary or lower secondary education), intermediate (upper secondary, post-secondary non-tertiary education) and tertiary (bachelor, master, doctor or equivalent).$^{22}$ Occupational status was defined by working (full-time or parttime) and not working.

Reliable and valid measurements were used to assess neurological factors such as functional independence in basic ADL, cognitive impairment and severity of language impairment, respectively the Barthel index $(\mathrm{BI}),{ }^{23}$ the Montreal Cognitive Assessment (MoCA) ${ }^{24}$ and the Goodglass Aphasia Severity Rating Scale (GASRS, part of the Boston Diagnostic Aphasia Examination). ${ }^{25}$ Other independent variables that were documented: time between $\mathrm{ABI}$ and first contact, length of inpatient stay, number of contacts and match between peer supporter and patient characteristics (gender, age, diagnosis, cultural background, marital status, children, educational level, occupational status, sports). 
To get more insight into the need for and experience with peer support patients were asked to explain in more detail why they did or did not perceive a need for peer support and experienced the contact as meaningful or not. For this purpose, six answer options were given, based on prior research on peer support (online supplementary information, boxes 1 and 2) ${ }^{891626}$ Patients were allowed to deviate from these options in their answers. In addition, duration of contact, subject of conversation, whether or not a caregiver was part of the conversation and continuation of contact during outpatient rehabilitation were documented.

\section{Patient and public involvement}

The peer support intervention was developed in co-operation with the peer supporters themselves, who were able to represent the patient population. A working group consisting of an occupational therapist, a social worker, psychologist, physiotherapist and speech therapist made decisions regarding the match based on the primary impairment and the timing of the initial contact between peer supporter and patient. These decisions were evaluated and adjusted according to the experiences of those who applied peer support. The contents of the support were shaped by the peer supporters themselves, individually coached on the job by therapists (social worker, occupational therapist, speech therapist). The aim of this study was to improve the intervention and further research.

\section{Statistical analysis}

The inclusion of 120 patients was based on the assumption of one determinant per ten patients. Subjects of conversation, duration, number of contacts and explanation for 'need' and 'meaningful' were analysed using descriptive statistics. Factors of influence on the need for peer support and on meaningful contact were analysed using bivariate logistic regression analysis and calculating ORs and their 95\% CI. Determinants included in the logistic regression analyses were dichotomised to improve interpretability. Age was dichotomised at 60 years, based on the median and on the expected difference in working and family life for $<60$ and $\geq 60$ years. Time between ABI and first assessment, first contact and length of stay were dichotomised based on the calculated median. Time between $\mathrm{ABI}$ and discharge was dichotomised at $<3$ months and $>3$ months. ${ }^{27}$ Patients were divided into two groups based on their BI scores: <19ADL-dependent and $\geq 19$ independent for basic-ADL. ${ }^{28}$ Although there is no consensus on the cut-off for MoCA, ${ }^{29}$ the cut-off for the current population was set at $22^{30}$ which also corresponds with the median value. The GASRS was dichotomised at scores $0-2$ (severe aphasia) and 3-5 (moderate to mild aphasia). ${ }^{31}$ Significant determinants $(\mathrm{p}<0.05)$ were derived from the bivariate logistic regression analysis for 'need for peer support'. To predict if patients would perceive contact with a peer supporter as 'meaningful' in the future, a multivariate logistic model was developed using significant determinants $(p<0.10)$ from

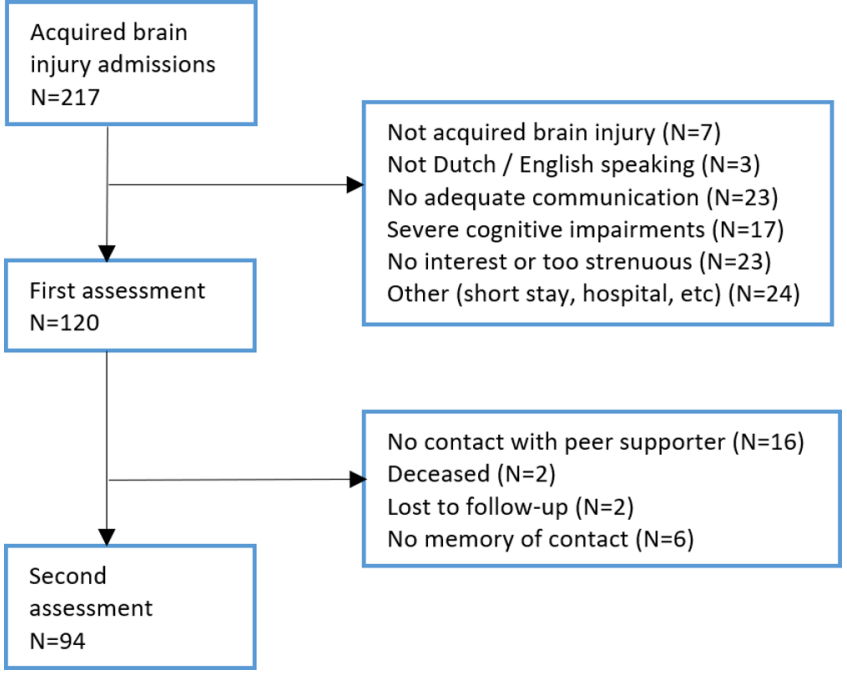

Figure 2 Flow chart of first assessment 2 weeks after admission and second assessment 1 week before or after discharge.

the bivariate logistic regression analysis. Collinearity between the determinants included was defined if their correlation coefficient was 0.7 or higher. Determinants with the highest odds ratios were included in the multivariate logistic regression model using a backward stepwise method. Subsequently, probabilities were calculated using the multivariable logistic model. In order to determine the accuracy of the model the classification table was used to calculate sensitivity, specificity and positive and negative predicted values by applying the following equation: $\quad P_{-} 1 /\left(1_{-}\left(\exp ^{[(\mathrm{B} 0+\mathrm{B} 1 \mathrm{X} 1+\mathrm{B} 2 \mathrm{X} 2+\mathrm{B} 3 \mathrm{X} 3 \ldots+\mathrm{BnXn})]}\right)\right)$. All significance levels were set two-tailed with a $\mathrm{p}$ value of $<0.05$ by using Statistical Package for Social Sciences (SPSS) Version 24.0 for Windows.

\section{RESULTS}

From 217 admissions, 120 patients were included in this study. Reasons for exclusion are shown in figure 2. All 120 patients participated in the first assessment, on average 30 days after ABI. However, the MoCA could not be administered to 11 patients due to severe aphasia. After the first assessment, 16 patients were not able to meet a peer supporter because of reasons such as early discharge, admission into hospital, and so on. Two patients died, six had no memory of contact with the peer supporter and two other patients were lost to follow-up. As a result, 94 participants participated in the second assessment at discharge (see figure 2). Baseline characteristics for participants included in the cohort are shown in table 2. Peer supporter characteristics are presented in table 1.

In general, $73.3 \%$ of the 120 included patients $(n=88)$ expressed a need for peer support, 2 weeks after admission for inpatient rehabilitation. 26.7\% $(n=32)$ did not perceive this need. In table 3 candidate determinants are presented, associated with the need for peer support, as determined by logistic regression analysis. Single patients 
Table 2 Patient characteristics

\begin{tabular}{ll}
\hline Variable & $\begin{array}{l}\text { Participants } \\
(\mathbf{n = 1 2 0})\end{array}$ \\
\hline Demographic factors & \\
\hline Gender, male (\%) & $73(61 \%)$ \\
\hline Age in years* & $60.6(50-68.1)$ \\
\hline Cultural background, Western (\%) & $85(71 \%)$ \\
\hline Marital status, married or relationship (\%) & $64(53 \%)$ \\
\hline Children, yes (\%) & $83(69 \%)$ \\
\hline Educational level & \\
\hline \multicolumn{1}{|c}{ Lower (\%) } & $24(20 \%)$ \\
\hline Intermediate(\%) & $47(39 \%)$ \\
\hline$\quad$ Tertiary (\%) & $49(41 \%)$ \\
\hline Occupational status, working (\%) & $61(51 \%)$ \\
\hline Sports, yes (\%) & $59(49 \%)$ \\
\hline Neurogiol factors
\end{tabular}

Neurological factors

Type of $A B I$

\begin{tabular}{|c|c|}
\hline ICVA (\%) & $71(59 \%)$ \\
\hline $\mathrm{ICH}(\%)$ & $12(10 \%)$ \\
\hline Trauma & $12(10 \%)$ \\
\hline other & $25(21 \%)$ \\
\hline GASRS score $^{*}(0-5) \ddagger$ & $5(4-5)$ \\
\hline BI total score* $(0-20)$ & $18(12.3-20)$ \\
\hline $\operatorname{MoCA}^{*}(0-30) n=109$ & $22(19-25.5)$ \\
\hline \multicolumn{2}{|l|}{ Other factors } \\
\hline $\begin{array}{l}\text { Time between } \mathrm{ABI} \text { and first assessment, } \\
\text { days }{ }^{*}\end{array}$ & $30(24-42.5)$ \\
\hline Length inpatient stay* & $59.5(37-97.25)$ \\
\hline Time between $\mathrm{ABI}$ and discharge, days $\dagger$ & $78(54-116.5)$ \\
\hline
\end{tabular}

*Median values (interquartile ranges).

†Median values (interquartile ranges), $n=118$ ( $n=2$ deceased). fscore 5: very slight language impairment, which is only perceived by the patient himself/herself.

$\mathrm{ABI}$, acquired brain injury; $\mathrm{BI}$, Barthel index; GASRS, Goodglass Aphasia Severity Rating Scale; $\mathrm{ICH}$, intracerebral haemorrhage; ICVA, Ischaemic cerebrovascular accident; MoCA, Montreal Cognitive Assessment; $n$, number of patients.

perceived a significantly higher need for peer support than patients who were in a relationship. Also, those with a non-Western cultural background expressed a significantly higher need for peer support when compared with patients with a Western background. Other factors did not show a significant influence on the perceived need for peer support.

After the first assessment, the initial contact between the peer supporter and patient took place. The average number of contacts between patient and peer supporter was 2.3 (SD, 2.4, range 1-19) and all of them were faceto-face in the rehabilitation centre. Of the 94 participants who received peer support $51.5 \%$ had more than one appointment with a peer supporter. Most subsequent contacts were with the same peer supporter as in the initial contact. During the course of the research some patients were referred to another peer supporter if a better match with regard to impairments (aphasia) or social status (specific practical advice on, for instance, one handed childcare or upbringing of a child after ABI) was expected. The average length of initial contact was $20 \mathrm{~min}$ (SD 10.07, ranging from 5 to $45 \mathrm{~min}$ ) planned on the patients personal therapy schedule. Average length of subsequent contact was $24 \mathrm{~min}$ (SD 14.33, ranging from 5 to $60 \mathrm{~min}$ ) either planned on the therapy schedule or spontaneously organised in between therapy sessions. Almost all contacts (95\%) were single face-toface contacts; the other $5 \%$ were either together with a partner/family member, or partner/family member met the peer supporter alone. Fifty-four percent of the 120 participants $(n=65)$ returned to the rehabilitation centre after discharge for outpatient rehabilitation services of which $29 \%(n=19)$ continued their contact with the same peer supporter.

After discharge $76.6 \%$ of the 94 patients $(\mathrm{n}=72)$ scored contact with the peer supporter as meaningful, while $23.4 \%(n=22)$ did not perceive the contact as meaningful. In table 4 candidate determinants are presented, associated with a perceived meaningful contact or not, as determined by logistic regression analysis.

Patients younger than 60 years of age perceived their contact significantly more meaningful than older patients. Another significant difference was found for patients with a time between $\mathrm{ABI}$ and discharge of longer than 3 months; they perceived their contact more meaningful than patients with a shorter time between $\mathrm{ABI}$ and discharge. 'Age', and 'time between ABI and discharge' were entered into a multivariable model as shown in table 5. The probability for a meaningful contact for patients with an age below 60 years and a time between the onset of $\mathrm{ABI}$ and discharge of more than 3 months was estimated at 0.93 . For patients older than 60 and a shorter time between $\mathrm{ABI}$ and discharge the probability was estimated at 0.55 . Analysis showed a sensitivity of 0.54 (95\% CI, 0.42 to 0.66$)$ and a specificity of 0.77 (95\% CI, 0.66 to 0.84$)$. The positive predictive value was $0.87(95 \%$ CI, 0.73 to 0.94 ) and the negative predictive value 0.33 (95\% CI, 0.20 to 0.48 ).

When expressing a need for peer support, most patients expected practical advice and information from the peer supporter $(27 \%, \mathrm{n}=24)$. If they did not express a need for peer support, patients expected that it would not help them right now but maybe later in the process $(22 \%, n=7)$. An overview of the answers is shown in online supplementary appendix, box 1 . In the second assessment patients were asked to explain why they experienced their contact as meaningful or not. Most patients that scored their contact as meaningful experienced mutual recognition and understanding $(38 \%, \mathrm{n}=27)$. When contact was not meaningful, patients explained that it had no added value to their rehabilitation process $(41 \%, \mathrm{n}=9)$. All answers are shown in supplementary appendix, box 
Table 3 Candidate determinants, measured within first 2 weeks after admission, associated with patients' 'perceived need for peer support' $(y / n)$ during inpatient rehabilitation, as determined by unadjusted bivariate logistic regression analyses $(n=120)$

\begin{tabular}{|c|c|c|c|}
\hline Determinant & OR & $95 \% \mathrm{Cl}$ & $P$ value \\
\hline Gender (M/F) & 1.1 & $0.48-2.53$ & 0.822 \\
\hline Age $(0<60 ; 1 \geq 60)$ & 0.78 & $0.35-1.76$ & 0.545 \\
\hline Type of ABI (ICVA vs other) & 1.45 & $0.63-3.37$ & 0.387 \\
\hline Cultural background (Western vs non-Western) & 5.52 & $1.56-19.58$ & 0.008 \\
\hline Marital status (relationship vs no relationship) & 0.42 & $0.18-0.98$ & 0.044 \\
\hline Educational level (low/intermediate vs tertiary) & 1.75 & $0.74-4.13$ & 0.201 \\
\hline Occupational status (working vs not working) & 0.96 & $0.43-2.15$ & 0.912 \\
\hline Bl total score $(0<19 ; 1 \geq 19)$ & 0.82 & $0.37-1.85$ & 0.637 \\
\hline $\operatorname{MoCA}(0 \leq 22 ; 1>22)^{\star}$ & 0.89 & $0.38-2.08$ & 0.784 \\
\hline Time between $\mathrm{ABI}$ and first assessment $(0 \leq 30 ; 1>30)$ & 1.23 & $0.54-2.77$ & 0.62 \\
\hline
\end{tabular}

${ }^{*} n=109$ : total MoCA values are not available for patients with severe aphasia $(n=11)$.

$\mathrm{ABI}$, acquired brain injury; $\mathrm{BI}$, Barthel index; ICVA, ischaemic cerebrovascular accident; MoCA, Montreal Cognitive Assessment; $n$, number of patients.

2. Figure 3 presents the subjects of conversation that patients were interested in before the initial contact and subjects discussed during contact with the peer supporter. Overall, main subjects of conversation were future expectations and coping/acceptance.

\section{DISCUSSION}

Peer support is considered a part of adequate rehabilitation services. ${ }^{67}$ Several studies suggest positive impact on patients with ABI and their caregivers. ${ }^{8} 91415$ To our knowledge, this is the first study that looked at characteristics of patients that may influence the benefit of peer support. In this study, $73 \%$ of patients $(n=88)$ expressed a need for peer support at admission, mostly driven by a need for practical advice and information and a better understanding of future expectations after brain injury. At discharge, $77 \% \quad(n=72)$ indicated that peer support had been meaningful, mostly based on a feeling of mutual recognition and understanding, underlining the positive impact of shared experiential knowledge and a sense of belonging reported in earlier research. ${ }^{513} 14$ Results showed that single patients expressed a significantly higher need for peer support than those within a relationship. Experiencing brain injury can increase feelings of loneliness and depression. ${ }^{814} 16$ Perhaps patients within a relationship experience support from their partner in terms of help, emotional support and advice. ${ }^{5}$ Patients without a 'natural helper' might therefore perceive a greater need

Table 4 Candidate determinants, measured at discharge, associated with contact perceived as 'meaningful or not' $(\mathrm{y} / \mathrm{n})$ during inpatient rehabilitation, as determined by unadjusted bivariate logistic regression analyses $(n=94)$

\begin{tabular}{|c|c|c|c|}
\hline Determinant & OR & $95 \% \mathrm{Cl}$ & $P$ value \\
\hline Gender (M/F) & 0.81 & $0.31-2.12$ & 0.667 \\
\hline Age $(0<60 ; 1 \geq 60)$ & 0.32 & $0.11-0.90$ & 0.032 \\
\hline Type of ABI (ICVA vs other) & 1.45 & $0.52-3.98$ & 0.476 \\
\hline Cultural background (Western vs non-Western) & 2.79 & $0.75-10.40$ & 0.127 \\
\hline Marital status (relationship vs no relationship) & 1.04 & $0.40-2.72$ & 0.934 \\
\hline Educational level (lower/intermediate vs tertiary) & 1.81 & $0.66-4.98$ & 0.248 \\
\hline Occupational status (working vs not working) & 0.59 & $0.22-1.54$ & 0.279 \\
\hline BI total score $(0<19 ; 1 \geq 19)$ & 1.62 & $0.59-4.45$ & 0.35 \\
\hline $\operatorname{MoCA}(0 \leq 22 ; 1>22)^{*}$ & 0.94 & $0.35-2.51$ & 0.898 \\
\hline Time between $\mathrm{ABI}$ and discharge ( $0 \leq 3$ mos.; $1>3$ months) & 2.83 & $1.03-7.79$ & 0.043 \\
\hline Match PS and patient $(0 \leq 4 ; 1>4$ matching characteristics $) \dagger$ & 1.25 & $0.47-3.35$ & 0.658 \\
\hline
\end{tabular}

${ }^{*} \mathrm{n}=86$ : total MOCA values are not available for patients with severe aphasia.

†characteristics: gender, age, type of $\mathrm{ABI}$, marital status, educational level, occupational status, children, sports.

$\mathrm{ABI}$, acquired brain injury; BI, Barthel index; ICVA, ischaemic cerebrovascular accident; MoCA, Montreal Cognitive Assessment; n, number of patients; PS, Peer supporter. 
Table 5 Probabilities for a meaningful contact, at discharge, $n=94$

Time ABI

discharge $>3$

\begin{tabular}{|c|c|c|c|c|c|c|}
\hline Age $<60$ & months & Probability & Sensitivity $(95 \% \mathrm{Cl})$ & Specificity $(95 \% \mathrm{Cl})$ & PPV $(95 \% \mathrm{Cl})$ & NPV $(95 \% \mathrm{Cl})$ \\
\hline \multicolumn{7}{|c|}{$\mathrm{P}=1 /\left(1+\left(\exp -\left(1.384+-1.182^{\star}\right.\right.\right.$ age+1.133*time $\mathrm{ABI}$ _discharge $\left.)\right)$} \\
\hline+ & + & 0.93 & $0.54(0.42-0.66)$ & $0.72(0.50-0.88)$ & $0.87(0.73-0.94)$ & $0.33(0.20$ to 0.48$)$ \\
\hline+ & - & 0.8 & & & & \\
\hline- & + & 0.79 & & & & \\
\hline- & - & 0.55 & & & & \\
\hline
\end{tabular}

+ , determinant is relevant for patient; -, determinant is not relevant for patient; ABI, acquired brain injury; n, number of patients; NPV, negative predictive value; $\mathrm{P}$, probability; PPV, positive predictive value.

for peer support. Also, some single patients may have been socially or emotionally more isolated before onset of $\mathrm{ABI}$ and therefore benefit more from available peer support. ${ }^{17}$ It should be taken into account that need for support may change over time, also for patients within a relationship. Quantity and quality of support from partners may be affected when they are subject to stress themselves because of their partners chronic illness. ${ }^{32} 33$ Further, the need for peer support among patients with a non-Western background was significantly higher than for those with a Western background. Patients from an ethnic minority background may experience more stress due to change of environment as a result of migration, lack of family or other social support, lower ability to influence the direction and course of life events and little or no reading skills. ${ }^{34}$ These factors may increase a need for available sources of support such as peer support. At discharge, patients younger than 60 years had experienced their contact significantly more meaningful than older patients. The available peer supporters were also aged under 60 which might have increased a feeling of mutual recognition. Patients beyond 3 months between onset of $\mathrm{ABI}$ and discharge perceived their contact significantly more meaningful than patients within the first 3 months of onset of ABI and discharge. Those with a time after onset beyond 3 months had twice as much contact with a peer supporter. It is likely that they had more opportunity to meet the peer supporter and perhaps a greater number of contacts was necessary to discuss subjects more extensively or build trust in the relationship. In addition, patients with a longer time between $\mathrm{ABI}$ and discharge were probably more severely affected by their brain injury, had a lack of social support or housing problems. Further, these patients had passed the time window of spontaneous neurological recovery ${ }^{27}$ which might have made them more aware of their functional prognosis and influenced their perception of their benefit from peer support. A few studies recommend that patient and peer supporter should be matched as closely or homogenously as possible. ${ }^{515}$ It was therefore expected that patients with similarity on a greater number of characteristics would consider their contact more meaningful. However, although the cut-off point between the two groups is disputable, there was no significant difference found between patients and peers with less than four common characteristics compared with those with more

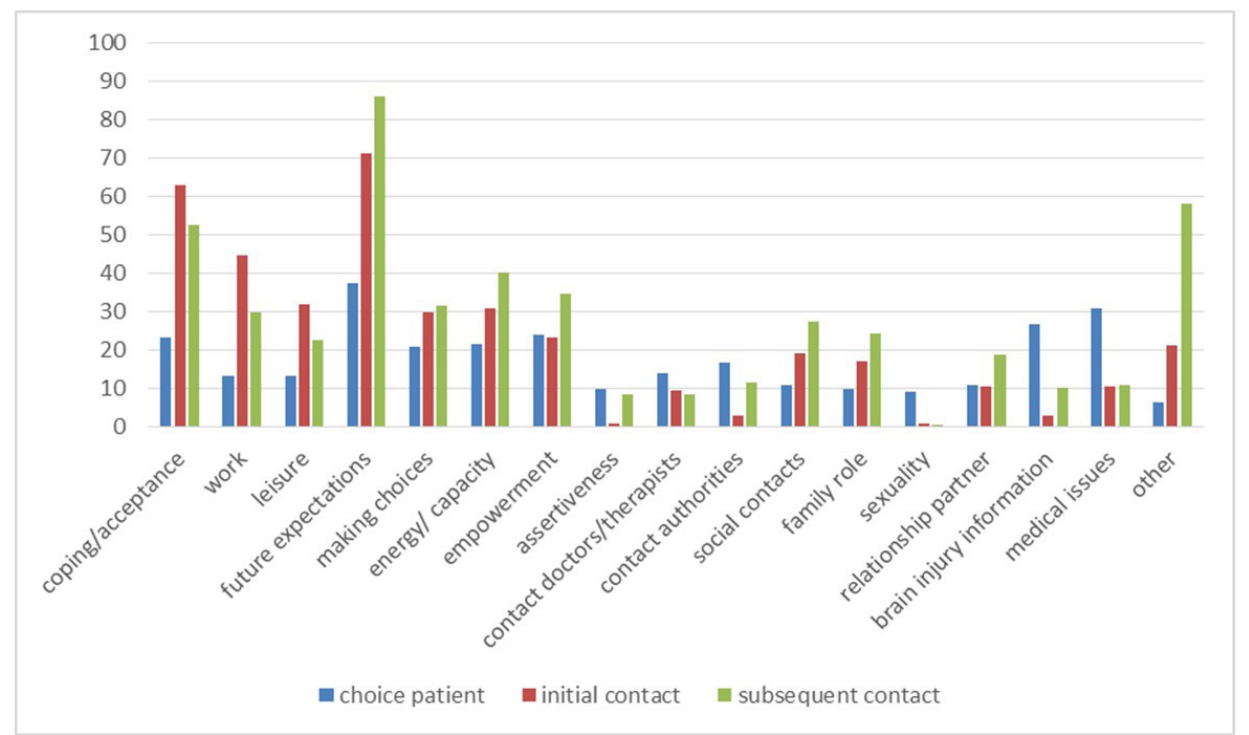

Figure 3 Subject(s) of conversation (\%) as chosen by patient, discussed in initial contact and in subsequent contact. 
than four matching characteristics. This finding suggests that contact perceived as meaningful is not significantly influenced by a higher number of similar characteristics but possibly by a match on specific characteristics. Unfortunately the prediction model for 'meaningful contact' had a low sensitivity and negative predicted value and therefore cannot predict who will not benefit from peer support. Also, in this model a high number of patients are withheld from peer support where they would in fact benefit from peer support.

Theory on social support describes a difference between perceived and received support. ${ }^{35} 36$ Perceived support considers that assurance of available support helps to appraise stressful events less negative. This can be measured by asking patients to evaluate the quality and availability of support. ${ }^{35}$ The use of the subjective outcomes 'need' and 'meaningful contact' in this study has been an effort to evaluate patients' perceptions on available peer support. It is also necessary to further investigate received support, actual support provided by others. This is said to enhance coping and accordingly decrease the effects of a stressor ${ }^{35}$ such as impairments after brain injury. The effect of peer support on coping has been studied in one RCT for TBI ${ }^{9}$ but should also be measured for other patients with ABI. Also, ingredients of received support such optimal dosage, length of contact, rehabilitation phase and strategy for the provision of emotional, informational and appraisal support should be further investigated.

This study has some limitations. First, the results do not describe the extent of 'need' and 'meaningful contact' for patients although the use of categories for further explanation gave more in-depth understanding of 'need' and 'meaningful contact' and help to define both concepts. Second, the primary outcomes 'need' and 'meaningful contact' were answered with 'yes' or 'no' by patients and it is possible that some patients gave socially desirable responses. The categories for further explanation allowed them to express more of their own opinion. Third, this study did not measure social support before onset of ABI such as support from family or other social networks. This would have provided a more comprehensive explanation for the significant need expressed by single patients and non-Western patients. In future studies social support before onset of ABI should be measured, as well as other forms of support during rehabilitation (social work, psychology and so on) to be able to identify the difference between the effect of peer support and other social support. Fourth, the number of patients with aphasia was small (16\%), and therefore, unfortunately, the possible influence of communicative impairments could not be investigated. A number of patients was excluded from the research due to severe communication problems or severe cognitive impairments. This should be kept in mind with regard to generalisability of the results. Although they were not included in this study, we know that some of these severely impaired patients did have in-depth contact with their peers. The generalisability of the results is also limited because the study was done in one rehabilitation centre and only for the inpatient population. It is important to compare rehabilitation phases for a better application of the peer support intervention. Fifth, the rehabilitation centre only had a small number of available peer supporters $(n=4)$ and the sample size was relatively small. Also, the peer supporters were quite homogeneous with regard to the level of education and cultural background. As a consequence, caution should be taken when interpreting the findings with regard to the match between patient and peer supporter. As discussed, the findings in this study suggest that for beneficial contact a match on specific characteristics might be necessary. Further research should point out which characteristics should be similar between peer supporter and patient for a significant benefit. A sixth limitation is that measurements were done in a heterogenic group and results can therefore not be linked to specific ABI subgroups. Stroke specific studies are lacking, but are needed in the future. Finally, there was no fixed protocol which led to differences in the application of peer support and consequently a greater variation of 'meaningful contact'. A next step would be to describe the protocol for peer intervention following the template for intervention description and replication checklist ${ }^{37}$ to provide a replicable description of the peer intervention for match, dosage, length of contact, rehabilitation phase and provision of emotional, informational and appraisal support, based on the current findings, the available literature and the theory of social support. ${ }^{35} 36$ The intervention can then be tested in a proof-of-concept trial to measure the effects for stroke survivors on outcomes such as coping, self-efficacy, depression and health-related quality of life. This will bring peer support from a 'hypothesised positive influence' to a new level of evidence-based practice for rehabilitation programmes.

Acknowledgements The authors would like to thank the peer supporters from Reade for their cooperation and willingness to document their work during the course of the research.

Contributors RW: substantial contributions to the conception/design/analysis and interpretation of the work and writing the article. RN and GK: revising the article critically and final approval of the version to be published.

Funding This study was funded by an award from the Duyvensz-Nagel Foundation. Competing interests None declared.

Patient consent for publication Not required.

Ethics approval This study was approved by the Medical Ethics Review Committee of the Slotervaart Hospital and Reade in Amsterdam (METC number P1401).

Provenance and peer review Not commissioned; externally peer reviewed.

Data sharing statement the raw data are available from the corresponding author on request

Open access This is an open access article distributed in accordance with the Creative Commons Attribution Non Commercial (CC BY-NC 4.0) license, which permits others to distribute, remix, adapt, build upon this work non-commercially, and license their derivative works on different terms, provided the original work is properly cited, appropriate credit is given, any changes made indicated, and the use is non-commercial. See: http:// creativecommons.org/licenses/by-nc/4.0/. 


\section{REFERENCES}

1. Majdan M, Plancikova D, Brazinova A, et al. Epidemiology of traumatic brain injuries in Europe: a cross-sectional analysis. Lancet Public Health 2016;1:e76-e83.

2. Feigin VL, Forouzanfar MH, Krishnamurthi R, et al. Global and regional burden of stroke during 1990-2010: findings from the Global Burden of Disease Study 2010. Lancet 2014;383:245-55.

3. Lo Buono V, Corallo F, Bramanti P, et al. Coping strategies and health-related quality of life after stroke. J Health Psychol 2017;22:16-28.

4. Polinder S, Haagsma JA, van Klaveren D, et al. Health-related quality of life after TBI: a systematic review of study design, instruments, measurement properties, and outcome. Popul Health Metr 2015;13:4.

5. Dennis CL. Peer support within a health care context: a concept analysis. Int J Nurs Stud 2003;40:321-32.

6. United Nations. Convention on the rights of people with disabilities. Article 26. http://www un org/disabilities/documents/convention/ convoptprot-e pdf

7. World Health Organization. World Report on Disability. http://who.int/ disabilities/world report/2011/en/

8. Struchen MA, Davis LC, Bogaards JA, et al. Making connections after brain injury: development and evaluation of a social peermentoring program for persons with traumatic brain injury. $J$ Head Trauma Rehabil 2011;26:4-19.

9. Hanks RA, Rapport LJ, Wertheimer J, et al. Randomized controlled trial of peer mentoring for individuals with traumatic brain injury and their significant others. Arch Phys Med Rehabil 2012;93:1297-304.

10. Salander P. Facilitating interventions and/or relationships in malignant brain tumors. Adv Ther 2010;27:17-27.

11. Wobma R, Nijland RH, Ket JC, et al. Evidence for peer support in rehabilitation for individuals with acquired brain injury: A systematic review. J Rehabil Med 2016;48:837-40.

12. Morris RP, Fletcher-Smith JC, Radford KA. A systematic review of peer mentoring interventions for people with traumatic brain injury. Clin Rehabil 2017;31:1030-8.

13. Morris R, Morris P. Participants' experiences of hospital-based peer support groups for stroke patients and carers. Disabil Rehabil 2012;34:347-54

14. Kessler D, Egan M, Kubina LA. Peer support for stroke survivors: a case study. BMC Health Serv Res 2014;14:256.

15. Stewart MJ, Doble S, Hart G, et al. Peer visit support for family caregivers of seniors with stroke. Can J Nurs Res 1998;1:87-117.

16. Hibbard MR, Cantor J, Charatz $\mathrm{H}$, et al. Peer support in the community: initial findings of a mentoring program for individuals with traumatic brain injury and their families. J Head Trauma Rehabil 2002;17:112-31.

17. Cohen S, Gottlieb B, Underwood LG. Social Relationships and Health. In: Cohen S, Underwood LG, Gottlieb B, eds. Social Support Measurement and Intervention: a guide for health and social scientists. Toronto: Oxford University Press, 2000.

18. von Elm E, Altman DG, Egger M, et al. Strengthening the Reporting of Observational Studies in Epidemiology (STROBE) statement: guidelines for reporting observational studies. BMJ 2007;335:806-8.
19. Turner-Stokes L. Britisch Society of Rehabilitation Medicine, Royal College of Physicians. Rehabilitation following acquired brain injury. London: RCP, BSRM, 2003.

20. Headway the brain injury association. Acquired Brain Injury: The numbers behind the hidden disability 2015. 2015. https://www. headway.org.uk/media/2881/brain-injury-statistics-methodologyinjury-categories-and-further-notes.pdf

21. Statistics Netherlands (CBS). Definitions Statistics Netherlands 2017 2017. https://www.cbs.nl/en-gb/our-services/methods/definitions

22. UNESCO Institute for Statistics. International Standard Classification of Education. 2011. http://uis.unesco.org/sites/default/files/ documents/international-standard-classification-of-education-isced2011-en.pdf

23. Collin C, Wade DT, Davies S, et al. The Barthel ADL Index: a reliability study. Int Disabil Stud 1988;10:61-3.

24. Cumming TB, Bernhardt J, Linden T. The montreal cognitive assessment: short cognitive evaluation in a large stroke trial. Stroke 2011;42:2642-4.

25. Goodglass H, Kaplan E, Baressi B. Boston Diagnostic Aphasia Examination. 3rd edn. Philadelphia: Williams \& Wilkins, 2000.

26. Haas BM, Price L, Freeman JA. Qualitative evaluation of a community peer support service for people with spinal cord injury. Spinal Cord 2013;51:295-9.

27. Langhorne P, Bernhardt J, Kwakkel G. Stroke rehabilitation. Lancet 2011;377:1693-702.

28. Uyttenboogaart M, Stewart RE, Vroomen PC, et al. Optimizing cutoff scores for the Barthel index and the modified Rankin scale for defining outcome in acute stroke trials. Stroke 2005;36:1984-7.

29. Wong A, Law LS, Liu W, et al. Montreal Cognitive Assessment: One Cutoff Never Fits All. Stroke 2015;46:3547-50.

30. Zuo L, Dong Y, Zhu R, et al. Screening for cognitive impairment with the Montreal Cognitive Assessment in Chinese patients with acute mild stroke and transient ischaemic attack: a validation study. BMJ Open 2016;6:e011310.

31. Nouwens F, Dippel DWJ, de Jong-Hagelstein M, et al. Rotterdam Aphasia Therapy Study (RATS) - 3: "The efficacy of intensive cognitive-linguistic therapy in the acute stage of aphasia"; design of a randomised controlled trial. Trials 2013;14:24.

32. Brisette I, Cohen S, Seeman T. Measuring Social Integration and Social Networks. In: Cohen S, Underwood LG, Gottlieb B, eds. Social support measurement and intervention: a guide for health and social scientists. Toronto: Oxford University Press, 2002:53-85.

33. Ostwald SK, Bernal MP, Cron SG, et al. Stress experienced by stroke survivors and spousal caregivers during the first year after discharge from inpatient rehabilitation. Top Stroke Rehabil 2009;16:93-104.

34. Green AR, Betancourt JR, Carrillo JE. Integrating social factors into cross-cultural medical education. Acad Med 2002;77:193-7.

35. Lakey B, Cohen S. Social support theory and measurement. In: Cohen S, Underwood LG, Gottlieb B, eds. Social support measurement and intervention: a guide for health and social scientists. Toronto: Oxford University Press, 2000:29.

36. Chronister JA, Johnson EK, Berven NL. Measuring social support in rehabilitation. Disabil Rehabil 2006;28:75-84.

37. Hoffmann TC, Glasziou PP, Boutron I, et al. Better reporting of interventions: template for intervention description and replication (TIDieR) checklist and guide. BMJ 2014;348:g1687. 